\title{
Changes in safety on England's roads: analysis of hospital statistics
}

\author{
Mike Gill, Michael J Goldacre, David G R Yeates
}

\begin{abstract}
Objective To compare trends in the numbers of people with serious traffic injuries according to police statistics and hospital episode statistics (HES).

Design Descriptive study based on two independent population based data sources.

Setting Police statistics and hospital episode statistics in England.

Main outcome measures Rates of injury and death and their change over time reported in each data source, for 1996 to 2004.

Results According to police statistics, rates of people killed or seriously injured on the roads fell consistently from 85.9 per 100000 in 1996 to 59.4 per 100000 in 2004. Over the same time, however, hospital admission rates for traffic injuries were almost unchanged at 90.0 in 1996 and 91.1 in 2004. Both datasets showed a significant reduction in rates of injury in children aged $\leq 15$, but the reduction in hospital admission rates was substantially less than the reduction shown in the police statistics. The definition of serious injury in police statistics includes every hospital admission; in each year, none the less, the number of admissions exceeded the number of injuries reported in the police system.

Conclusions The overall fall seen in police statistics for non-fatal road traffic injuries probably represents a fall in completeness of reporting of these injuries.
\end{abstract}

\section{Introduction}

Government policy in England aims to reduce the number of people killed or seriously injured on the roads by $40 \%$ overall, and by $50 \%$ for those aged $\leq 15$, by 2010 compared with the baseline average rate in 1994-8. ${ }^{1}$ In the first review of progress, the Department for Transport used police statistics (the STATS19 system) to show that the number of people seriously injured in England had fallen by 21\% overall and by 32\% for children between the baseline years and 2002. ${ }^{1}$ While the number of children killed had fallen, however, the total number of adults killed had not. This contrasts with recent trends in continental Europe, where death rates have fallen more substantially than rates of non-fatal road injury. ${ }^{2}$ We wondered if the divergence between the figures for those killed and those seriously injured in England might have resulted, at least in part, from less complete reporting of non-fatal injuries in the police system. To understand these divergent trends, we analysed hospital admission statistics for traffic injuries in England.

\section{Method}

The Department for Transport provided us with STATS19 "Killed or Seriously Injured" data for England for 1996-2004. The STATS19 data are based on personal injuries that occur on public roads and that become known to the police. ${ }^{3}$ We analysed data on hospital admissions using the Department of Health's hospital episode statistics (HES) system for 1996-2004. We selected ICD-10 (international classification of diseases, 10th revision) codes for transport injuries, excluding admissions for non-traffic accidents. The HES system includes data about all people who go through a formal process of admission to a hospital ward, including people who do not stay in hospital overnight and excluding people who attend the emergency department but are not admitted.

\section{Results}

The police statistics showed a reduction in the number of people killed or seriously injured, with a fall from 1996 to 2004 (from 85.9 to 59.4 injuries per 100000 total population), but the hospital statistics did not (figure, table). Over the same period, the police statistics for non-fatal serious injuries alone fell from 79.7 to 54.0 per 100000 ; the corresponding figures for admissions for non-fatal injuries were 88.8 and 90.1 . We analysed admissions with a length of stay of two days or more as a proxy for severity of injury and found a small but significant reduction over time (table). To determine if a true fall in admission rates could have been masked by an increase in readmissions for the same injury, we used linked HES data, available for the financial years 1998-9 to 2002-3, to distinguish between episodes of admission and numbers of people admitted. There was no appreciable change over time in re-admission rates.

Both datasets showed a fall in all injuries and in non-fatal injuries in children aged $\leq 15$; but the fall in non-fatal injuries recorded in hospital statistics was much less than that in police statistics (table). For all ages combined, admission rates showed a significant decline for pedestrians; police statistics but not hospital statistics showed a decline for car occupants; and both sets of statistics showed a significant and substantial increase in admission rates for motorcyclists (table).

\section{Discussion}

Though police statistics suggest a reduction in serious traffic injuries in the past 10 years, ${ }^{13}$ hospital statistics show that there has been no appreciable reduction in injuries serious enough to warrant hospital admission. One possibility is that rates of

Another figure showing change in road injuries in the police statistics and HES is on bmj.com. 


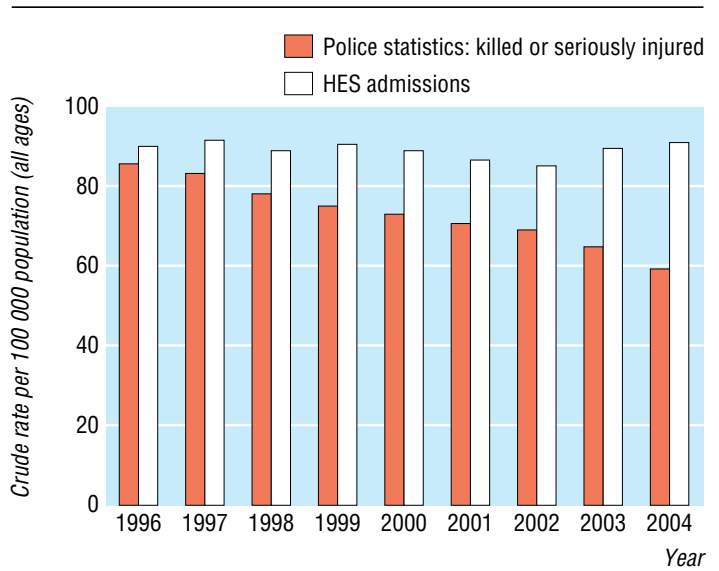

Traffic injury rates for England measured from police statistics for people killed or seriously injured and from admissions to hospital (HES), all ages

serious injury may have declined in the later years, and that those who were injured were increasingly more likely to have been admitted, such that equal and opposite effects on admission rates cancelled out each other. This, however, seems implausible. A second possibility is that trends in police and hospital statistics could have differed because of differences in definitions. The definition of serious injury in the police statistics includes all injuries resulting in hospital admission, but the definition is wider than this. If the reduction in injuries is real rather than an artefact, it can only have been a reduction in injuries that were not serious enough to warrant hospital admission. Furthermore, the fact that the police definition includes all hospital admissions, and that the hospital admission figures from HES are higher than the STATS19 figures, means that there must be under-reporting in the STATS19 system (confirming earlier research published for the Department for Transport $\left.{ }^{4}\right)$. The findings from hospital admission statistics cast doubt on whether there were reductions in serious road injuries from 1996 to 2004 and on whether the government's targets either overall or for children will be met by 2010 . The increase in deaths of motorcyclists and serious injuries requires further investigation in its own right.

Contributors: MG proposed the study. MG and MJG designed the study and wrote the first draft. DGRY analysed the data. All authors contributed to the final draft and are guarantors.

Funding: The Unit of Health-Care Epidemiology is funded by the English NHS National Co-ordinating Centre for Research Capacity Development. Competing interests: None declared.

Ethical approval: Central and South Bristol Multi-Centre Research Ethics Committee (04/Q2006/176).

1 Department for Transport. Tomorrow's roads-safer for everyone: the first three year review. London: Department for Transport, 2004

2 World Health Organization. European health for all database. www.euro.who.int/hfadb (accessed 16 June 2006).

Department for Transport's police statistics* and Department of Health's hospital episode statistics (HES) $†$ for traffic injuries in England, expressed as rates per 100000 population, ¥ with average annual percentage changes, 1996-2004

\begin{tabular}{|c|c|c|c|c|c|c|c|c|c|c|}
\hline $\begin{array}{l}\text { Source of injury statistics and type of injury } \\
\text { (ICD-10 codes } † \text { ) }\end{array}$ & 1996 & 1997 & 1998 & 1999 & 2000 & 2001 & 2002 & 2003 & 2004 & $\begin{array}{c}\text { Average annual percentage change } \\
1996-2004(95 \% \mathrm{CI})\end{array}$ \\
\hline Police: seriously injured or killed & 85.9 & 83.0 & 78.4 & 75.0 & 73.2 & 71.0 & 69.0 & 64.8 & 59.4 & $-4.1(-4.7$ to -3.5$)$ \\
\hline HES: traffic injuries (V01-V69) & 90.0 & 91.6 & 89.1 & 90.6 & 89.0 & 86.7 & 85.3 & 89.6 & 91.1 & $-0.2(-1.0$ to 0.5$)$ \\
\hline Police: seriously injured & 79.7 & 76.8 & 72.6 & 69.0 & 67.3 & 65.1 & 63.0 & 58.8 & 54.0 & $-4.4(-5.0$ to -3.8$)$ \\
\hline HES: non-fatal traffic injuries (V01-V69) & 88.8 & 90.5 & 87.9 & 89.6 & 88.0 & 85.7 & 84.3 & 88.6 & 90.1 & $-0.2(-1.0$ to 0.5$)$ \\
\hline Police: killed§ & 6.2 & 6.2 & 5.8 & 6.0 & 5.9 & 5.9 & 6.0 & 6.0 & 5.4 & $-1.0(-2.0$ to 0.0$)$ \\
\hline HES: fatal injuries§ (V01-V69) & 1.2 & 1.1 & 1.1 & 1.0 & 1.0 & 1.0 & 1.0 & 1.1 & 0.9 & $-2.2(-4.0$ to -0.3$)$ \\
\hline \multicolumn{11}{|l|}{ Children (age 0-15): } \\
\hline Police: seriously injured or killed & 58.8 & 54.7 & 51.6 & 48.2 & 44.3 & 42.8 & 39.4 & 35.5 & 34.4 & $-6.6(-7.1$ to -6.2$)$ \\
\hline HES: traffic injuries (V01-V69) & 107.8 & 109.3 & 101.4 & 110.1 & 103.5 & 101.1 & 90.6 & 94.8 & 97.3 & $-1.9(-3.2$ to -0.6$)$ \\
\hline Police: seriously injured & 56.5 & 52.5 & 50.0 & 46.4 & 42.7 & 40.9 & 37.8 & 34.0 & 32.9 & $-6.7(-7.1$ to -6.3$)$ \\
\hline HES: non-fatal traffic injuries & 107.2 & 108.6 & 101.1 & 109.7 & 103.0 & 100.6 & 90.4 & 94.3 & 97.0 & $-1.9(-3.2$ to -0.6$)$ \\
\hline Police: killed§ & 2.3 & 2.2 & 1.6 & 1.8 & 1.6 & 1.9 & 1.6 & 1.4 & 1.5 & $-4.8(-7.6$ to -2.0$)$ \\
\hline HES: fatal injuries§ (V01-V69) & 0.6 & 0.7 & 0.4 & 0.5 & 0.5 & 0.5 & 0.3 & 0.5 & 0.3 & $-7.0(13.1$ to -0.5$)$ \\
\hline \multicolumn{11}{|l|}{ Pedestrians: } \\
\hline Police & 20.3 & 19.4 & 18.4 & 17.1 & 16.7 & 15.8 & 15.0 & 13.8 & 12.8 & $-5.5(-6.0$ to -4.9$)$ \\
\hline HES (V01-V09) & 20.6 & 20.9 & 20.4 & 19.5 & 18.8 & 18.7 & 17.7 & 17.2 & 17.6 & $-2.5(-3.1$ to -1.9$)$ \\
\hline \multicolumn{11}{|l|}{ Cyclists: } \\
\hline Police & 7.1 & 6.8 & 6.2 & 5.9 & 5.2 & 4.9 & 4.5 & 4.4 & 4.2 & $-6.8(-7.6$ to -6.0$)$ \\
\hline HES (V10-V19) & 19.6 & 20.1 & 18.8 & 20.2 & 18.5 & 16.9 & 15.2 & 17.6 & 18.1 & $-2.2(-4.3$ to -0.3$)$ \\
\hline \multicolumn{11}{|l|}{ Motorcycle riders: } \\
\hline Police & 11.7 & 12.0 & 12.0 & 12.7 & 13.5 & 13.2 & 13.6 & 13.9 & 12.0 & $1.4(-0.4$ to 3.2$)$ \\
\hline HES (V20-V29) & 13.9 & 14.6 & 14.8 & 16.6 & 17.8 & 18.1 & 19.0 & 20.8 & 19.9 & 5.3 (4.2 to 6.4$)$ \\
\hline \multicolumn{11}{|l|}{ Car occupants: } \\
\hline Police: & 42.4 & 40.5 & 37.6 & 35.3 & 34.1 & 33.3 & 32.3 & 29.3 & 27.4 & $-5.0(-5.6$ to -4.4$)$ \\
\hline HES १(V30-V49) & 32.4 & 32.4 & 31.6 & 30.9 & 30.4 & 29.8 & 30.1 & 30.8 & 32.1 & $-0.5(-1.5$ to 0.4$)$ \\
\hline \multicolumn{11}{|l|}{ Other road users: } \\
\hline Police & 4.3 & 4.2 & 4.1 & 4.0 & 3.8 & 3.6 & 3.6 & 3.3 & 3.0 & $-4.2(-5.1$ to -3.2$)$ \\
\hline HES (V50-V69) & 2.3 & 2.5 & 2.4 & 2.4 & 2.5 & 2.2 & 2.4 & 2.2 & 2.4 & $-0.5(-2.0$ to 1.0$)$ \\
\hline HES: injuries with stay of at least 2 days & 49.8 & 50.3 & 48.7 & 49.1 & 48.5 & 47.8 & 46.5 & 47.5 & 45.8 & $-1.0(-1.4$ to -0.7$)$ \\
\hline
\end{tabular}

*Department for Transport's Killed or Seriously Injured Statistics, compiled in the STATS19 system.

†Analysed by using the field Epiorder=1 to count admissions rather than "finished consultant episodes," using ICD-10 codes for transport accidents (V01-V69), excluding admissions coded as non-traffic accidents.

tCrude rates for all ages; denominator restricted to people aged $\leq 15$ in the data for children.

$\S$ Police statistics include all deaths outside hospital and all in hospital within 30 days of sustaining injury; HES include only deaths in hospital after injury.

IIncludes three wheeled vehicles. 


\section{What is already known on this topic}

It is government policy in England to reduce substantially the number of people killed or seriously injured on the roads

Non-fatal serious injuries reported through the police fell substantially from 1996 to 2004

\section{What this study adds}

The reduction in non-fatal road traffic injuries reported in police statistics probably represents an increase in under-reporting of these injuries, or a reduction in minor injuries, or both

Hospital statistics show that there has been no appreciable reduction in injuries that are serious enough to warrant hospital admission
3 Department of Transport/National Statistics. Road accident statistics (STATS19 returns). www.statistics.gov.uk/STATBASE/Source.asp?vlnk $=571$ (accessed 16 June 2006)

4 Simpson HF. Comparison of hospital and police casualty data: a national study. Crowthorne: Transport Research Laboratory, 1996 (TRL report 173).

(Accepted 1 April 2006)

doi $10.1136 /$ bmj.38883.593831.4F

South East Public Health Group, Government Office for the South East, Guildford, Surrey GU1 4GA

Mike Gill regional director of public health

Unit of Health-Care Epidemiology, Department of Public Health, Oxford University, Oxford OX3 7LF

Michael J Goldacre professor of public health

David G R Yeates computer scientist

Correspondence to: M J Goldacre michael.goldacre@dphpc.ox.ac.uk 